\title{
Effect of Superparamagnetic Iron Oxide Nanoparticles on Glucose Homeostasis on Type 2 Diabetes Experimental Model
}

Lamiaa M.A. Ali ${ }^{\mathrm{a}, \mathrm{b}^{* *}}$, Sara A. Shaker ${ }^{\mathrm{a}}$, Rafael Pinol ${ }^{\mathrm{c}}$, Angel Millan ${ }^{\mathrm{c}^{*}}$, Mervat Y. Hanafy ${ }^{\mathrm{a}}$, Madiha H. Hemly ${ }^{\mathrm{a}}$, Maher A. Kamel ${ }^{\mathrm{a} * *}$, Shimaa A. Mahmoud ${ }^{\mathrm{a}}$

${ }^{a}$ Biochemistry Department, Medical Research Institute, Alexandria University, Egypt.

${ }^{\mathrm{b}}$ Institut des Biomolécules Max Mousseron UMR 5247 CNRS, UM-Faculté de Pharmacie, 15 Avenue Charles Flahault, 34093, Montpellier cedex 05, France.

'Instituto de Ciencia de Materiales de Aragon (ICMA)-CISC, Zaragoza University, Spain.

Corresponding authors:

Lamiaa M.A. Ali ${ }^{\mathrm{a}, \mathrm{b}^{* *}}$, Maher A. Kamel $^{\mathrm{a} * *}$, Angel Millan $^{\mathrm{c} *}$

\section{Affiliation/address:}

$\mathrm{a}^{* *}$ Medical Research Institute-Alexandria University, 165 El-Horreya Avenue, EL-Hadara, POB: 21561, Alexandria, Egypt.

$\mathrm{c}^{*}$ Instituto de Ciencia de Materials de Aragon, Facultad de Ciencias, C/pedro Cerbuna 12, Plaza san Francisco, 50009, Zaragoza, Spain.

\section{Telephone:}

$\mathrm{a}^{* *}+2034285455$ Ext (524 or 581)

$c^{*}+34876553347$

\section{Email:}

a,b** miss limo@yahoo.com

$\mathrm{a}^{* *}$ maher.kamel@alexu.edu.eg

c*amillan@unizar.es 


\section{$\underline{\text { Abstract: }}$}

Aims: Evaluation of the anti-diabetic effect of superparamagnetic iron oxide nanoparticles (SPIONs) on Type 2 diabetic rats and compared their effect to metformin treatment.

Main methods: Diabetic rats were treated with different doses of nanoparticles one time per week for 4 weeks. Fasting blood glucose level was determined for studied groups during the experimental period (30 days). At the end of the experiment, oral glucose tolerance test was carried out, serum samples were collected for biochemical assays. Then animals were sacrificed to obtain tissues for assessment of glucose transporters, insulin receptors and insulin signaling proteins.

Key finding: SPIONs treatment normalized fasting blood glucose and lowering insulin level in diabetic rats compared to untreated diabetic rats. SPIONs significantly ameliorate the glucose sensing and the active components of insulin signaling pathway. The anti-diabetic effects of SPIONs may be mediated through its effect on (i) hepatic peroxisome proliferator-activated receptor gamma coactivator 1 -alpha content, which induced by SPIONs treatment in a dosedependent manner, (ii) adipocytokines as SPIONs treated diabetic rats showed significantly higher levels of adiponectin and lower retinol binding protein 4 compared to untreated diabetic rats, (iii) lipid profile as SPIONs treatment significantly corrected the lipid profile in a dosedependent manner and to a similar extent as metformin or even better.

Significance: To our knowledge, this is the first study that explores the anti-diabetic effects of SPIONs on diabetic model.

\section{Key Words:}

Diabetes; Glucose sensing; Insulin resistance; Nanoparticles; Superparamagnetic iron oxide nanoparticles; SPIONs. 


\section{Introduction}

Type 2 diabetes mellitus (T2DM) represents one of the major epidemic health problem, more than 420 million have diabetes, with a projected global prevalence of 642 million by 2040 . This accelerating pandemic comes with high personal and financial costs to the individual, society, and the economy. T2DM is a chronic metabolic disorder of fuel homeostasis; it arises from the inability of islet $\beta$ cells to secrete adequate amount of insulin in response to varying degrees of overnutrition, inactivity, consequential overweight or obesity, and insulin resistance [1]. Treatment of diabetes encompasses the use of synthetic oral hypoglycemic agents and insulin. However, they are expensive, produce serious side effects and require daily dosing [2].

Last few years witness a general trend devoted for the use of nanomaterials for biomedical applications. Among those superparamagnetic iron oxide nanoparticles (SPIONs) that show interesting properties such as superparamagnetism and low toxicity. Therefore, they are involved in many biomedical applications either as diagnostic, therapeutic or theranostic tool such as hyperthermia [3], drug delivery [4], magnetic resonance imaging [5] and cell separation [6].

Metals play a vital role in different metabolic pathways such as glucose metabolism. Therefore, the anti-diabetic effect of zinc oxide, silver, gold, and core-shell silver-gold nanoparticles has been reported [7, 8]. In addition, Sharifi et al. reported that SPIONs down regulate the majority of high-risk genes involved in the development of T2DM in human primary adipocytes such as PPAR- $\gamma$, IGF2BP2, WFS1, JAZF1,CAMK1D, PRC1, TCF7L2 and ZFAND6 [9].

During the last few years we have been developing synthetic multifunctional platform for SPIONs based on the use of polymers that has good blood biocompatibility [10], low toxicity [11], and good relaxometry [12]. This model is composed of rounded shape maghemite $(\gamma-$ $\mathrm{Fe}_{2} \mathrm{O}_{3}$ ) magnetic [10-12] nanoparticles with a mean size of $10 \mathrm{~nm}$, these small nanoparticles are agglomerated to form clusters of 3-5 nuclei with a mean size of around $23 \mathrm{~nm}$. These agglomerated nuclei are coated with a hydrophilic polymer, polyethylene glycol (PEG), in order to increase solubility, stability, and biocompatibility. Different molecular weights of PEG (550 and $2000 \mathrm{Da}$ ) were used. 
Herein, we highlight the anti-diabetic potential of superparamagnetic iron oxide nanoparticles on T2DM experimental model.

\section{Materials and Methods}

All reagents and solvents were of commercial reagent grade and were used as received without further purification. Methoxy Poly(ethylene glycols) (MeOPEG2000, Mn: 2000 Da; MeOPEG500, Mn: $550 \mathrm{Da}$ ), diethylvinylphosphate (DEVP), Tosyl Chloride (TsCl), triethyl amine $\left(\mathrm{Et}_{3} \mathrm{~N}\right)$, sodium azide $\left(\mathrm{NaN}_{3}\right)$, triphenylphosphine (TPP), diethylvinylphosphate (DEVP) and trimethylbromosilane (TMBS) were purchased from Aldrich. Maghemite nanoparticles ( $\gamma$ $\mathrm{Fe}_{2} \mathrm{O}_{3}$ ) and the stock acid ferrofluid suspension were prepared following the method previously described [13]. In order to confer to these nanoparticles high solubility, stability in aqueous solutions and biocompatibility, nanoparticles were coated with bis(phosphonic) functional polyethylenglycols MeOPEG-N($\left(\mathrm{C}_{2} \mathrm{H}_{4} \mathrm{PO}_{3} \mathrm{H}_{2}\right)_{2}$, prepared by reaction of methoxy polyethylene glycol amine derivatives with commercial diethyl vinylphosphonate followed by hydrolysis of the phosphates esters by adapting the method previously described by N. Pothayee et al [14]. The synthetic procedure and characterization of all the polyethylene glycols are described in detail in Electronic Supplementary Information (ESI). The molecular structure and purity of all polyethylene glycol derivatives used in this work were confirmed by Nuclear magnetic resonance (NMR), and Infrared spectroscopy (IR). Proton $\left({ }^{1} \mathrm{H}\right)$, carbon $\left({ }^{13} \mathrm{C}\right) \mathrm{NMR}$ and phosphor $\left({ }^{31} \mathrm{P}\right)$ NMR spectra were recorded at room temperature solvent in a BRUKER AV-400 spectrometer $\left(400 \mathrm{MHz}\left({ }^{1} \mathrm{H}\right), 100 \mathrm{MHz}\left({ }^{13} \mathrm{C}\right),\left({ }^{31} \mathrm{P}\right) 162 \mathrm{mHz}\right)$ using $\mathrm{CDCl}_{3}$ or $\mathrm{D}_{2} \mathrm{O}$ as solvent. ${ }^{1} \mathrm{H}$ and ${ }^{13} \mathrm{C}$ and ${ }^{31} \mathrm{P}$ chemical shifts $(\delta)$ are reported in ppm and are referenced to the solvent peak the coupling constants $(\mathrm{J})$ are given in Hz. FT-IR spectra were recorded in a Perkin Elmer Spectrum 100 FT-IR spectrometer equipped with a Universal ATR sampling accessory. The spectra were collected over the range $4000-380 \mathrm{~cm}^{-1}$ and ATR correction was performed.

\subsection{Synthesis of the Ferrofluids and Characterization}

\section{Synthesis of sample SPION-PEG-550}

MeOPEG550-N( $\left.\mathrm{C}_{2} \mathrm{H}_{4} \mathrm{PO}_{3} \mathrm{H}_{2}\right)_{2}(194 \mathrm{mg}, 0.25 \mathrm{mmol}$, Mw: $774 \mathrm{Da})$ was dissolved in 10 $\mathrm{mL}$ of the $\gamma-\mathrm{Fe}_{2} \mathrm{O}_{3}$ nanoparticles ferrofluid $\left(\gamma-\mathrm{Fe}_{2} \mathrm{O}_{3}\right.$ original concentration was $\left.4 \mathrm{~g} / \mathrm{L}\right)$. After 
stirring for 10 minutes the $\mathrm{pH}$ was raised to 7.4 by dropwise addition of $\mathrm{NaOH}(1 \mathrm{M})$. The colloidal suspension was stirred for 1 hour at room temperature, and then sonicated (4 min) and filtered through 0.45 and $0.22 \mu \mathrm{m}$ nitrocellulose membrane filters (Millipore). Ferrofluid was purified by magnetic separation using a MidiMACS ${ }^{\mathrm{TM}}$ Separator and a LS column (MACS $^{\circledR}$ Miltenyi Biotec), washed with $\mathrm{NaCl} 150 \mathrm{mM}$ and finally collected in $10 \mathrm{~mL}$ of MilliQ water.

\section{Synthesis of sample SPION-PEG-2000}

MeOPEG2000-N( $\left.\mathrm{C}_{2} \mathrm{H}_{4} \mathrm{PO}_{3} \mathrm{H}_{2}\right)_{2}(540 \mathrm{mg}, 0.25 \mathrm{mmol}$, Mw: $2160 \mathrm{Da})$ was dissolved in 10 $\mathrm{mL}$ of the $\gamma-\mathrm{Fe}_{2} \mathrm{O}_{3}$ nanoparticles ferrofluid $\left(\gamma-\mathrm{Fe}_{2} \mathrm{O}_{3}\right.$ original concentration was $\left.4 \mathrm{~g} / \mathrm{L}\right)$. After stirring for 10 minutes the $\mathrm{pH}$ was raised to 7.4 by dropwise addition of $\mathrm{NaOH}(1 \mathrm{M})$. The colloidal suspension was stirred for 1 hour at room temperature, and then sonicated (4 min) and filtered through 0.45 and $0.22 \mu \mathrm{m}$ nitrocellulose membrane filters (Millipore). Ferrofluid was purified by magnetic separation using a MidiMACS ${ }^{\mathrm{TM}}$ Separator and a LS column $\left(\right.$ MACS $^{\circledR}$ Miltenyi Biotec), washed with $\mathrm{NaCl} 150 \mathrm{mM}$ and finally collected in $10 \mathrm{~mL}$ of MilliQ water.

\section{Chemico-Physical Characterization of the Ferrofluids}

Iron content in the SPIONs suspension was determined by Inductively Coupled Plasma Optical Emission Spectrometry (ICP-OES) in a plasma 40 ICP Perkin-Elmer spectrometer. Samples for ICP-OES were prepared by freeze drying the SPIONs suspensions and digestion of the solid in concentrated $\mathrm{HNO}_{3}$ overnight. Dynamic light scattering (DLS) and zeta potential measurements of ferrofluids were performed using a Malvern Zetasizer NS (Malvern Instruments Ltd., Worcestershire, UK) using a He-Ne laser with a $633 \mathrm{~nm}$ wavelength, a detector angle of $173^{\circ}$ at $25^{\circ} \mathrm{C}$. In the case of zeta potential measurements, the samples were set in a folded capillary cell, DTS 1060 (Malvern Instruments Ltd.). The measurements were performed after 1:20 dilution in ultra-pure water and were repeated at least three times on each sample to ensure consistency. Transmission electron microscopy (TEM) observations were carried out with a JEOL 2000-FXII microscope equipped with an Energy Dispersive X-ray (EDX) Microanalysis detector INCA. Infrared spectroscopy (FTIR) together with thermal analysis (TA) was performed to characterize the synthetized SPIONs and to confirm the attachment of the bis (Phosphonic) end capped PEG chains using in this work onto the iron oxide nanoparticles (see ESI). FTIR and TGA experiments were performed on freeze dried 
samples purified by magnetic separation. Thermogravimetric (TGA) and Differential thermogravimetric (DTA) analysis were performed using a simultaneous DTA-TGA unit SDT2960 (TA Instruments) in the range of $25^{\circ} \mathrm{C}$ to $700^{\circ} \mathrm{C}$ at a heating rate of $10^{\circ} \mathrm{C} / \mathrm{min}$ under air atmosphere.

\subsection{Experimental animals}

A total number of 90 albino Sprague-Dawley male rats, 2 months old were used. The animals were purchased from the animal house of Medical Research Institute, Alexandria University, Egypt. Rats were housed in standard cages in a well ventilated room $\left(25 \pm 2{ }^{\circ} \mathrm{C}\right)$, with a relative humidity of ( $43 \pm 3$ ), with free access to water and food and 12 hours light/dark cycle. The animals were acclimated to the animal facility before the onset of the experiments. Animal experiments were conducted in agreement with the Ethical Guidelines prescribed by the Medical Research Institute, Alexandria University Appendix 1, Guiding Principles for Biomedical Research Involving Animals, 2011. Necessary efforts were taken to respect 3Rs principle.

\section{Diabetes induction}

Diabetes was induced according to the method described by Srinivasan K, et al. [15], in which, rats were fed in-house prepared high-fat diet (HFD) for a period of 4 weeks. The HFD consisted of commercial rat chow, peanuts, milk chocolate and sweet biscuit in a proportion of $3: 2: 2: 1$. All components of the high-fat diet were ground and blended [16].

After 4 weeks of dietary manipulation, rats were injected intraperitoneally (IP) with low dose $(55 \mathrm{mg} / \mathrm{kg}$ ) of Streptozotocin (STZ) (Sigma chemicals, USA) dissolved in citrate buffer (pH 4.4) [17]. After 7 days of STZ injection, fasting blood glucose (FBG) level was measured by Glucometer (ACCU CHEK Active, Roche Co.). Rats with FBG level of $\geq 200 \mathrm{mg} / \mathrm{dL}$ were considered as diabetic and selected for the study.

\section{Experimental design}

Animals were classified into the following groups: 1) Control group that consists of 10 healthy male rats, 2) untreated-diabetic group that consists of 10 diabetic rats, 3) Metformin- 
treated diabetic group, which consists of 10 diabetic rats that were orally treated with metformin in a dose of $200 \mathrm{mg} / \mathrm{kg} /$ day for four weeks [18], 4) SPION-PEG-2000-treated diabetic group, in which diabetic rats were intravenously injected with SPION-PEG-2000 at a dose of 22, 44 and $66 \mu \mathrm{mol} \mathrm{Fe} / \mathrm{kg}$ once a week for four weeks [19], each dose contains 10 diabetics rats,5) SPIONPEG-550-treated diabetic group, in which diabetic rats were intravenously injected with SPION-PEG-550 at a dose of 22, 44, and $66 \mu \mathrm{mol} \mathrm{Fe} / \mathrm{kg}$ once a week for four weeks, each dose contains 10 diabetic rats.

\section{Collection of biological samples}

At the end of the experiment time (after 30 days), oral glucose tolerance test [20] was carried out for all groups. Then, animals in all studied groups were overnight fasting, then were anesthetized and serum samples were prepared by collecting the blood from the retro-orbital vein in anticoagulant free tubes, follow by centrifugation at $3000 \mathrm{xg}$ for $10 \mathrm{~min}$. These samples were used for the determination of serum glucose, insulin, lipid profile, alanine amino transferase (ALT), aspartate amino transferase (AST), urea , creatinine, retinol binding protein 4 (RBP4) and adiponectin. Then animals were sacrificed through cervical dislocation to obtain pancreatic tissue for the assessment of glucose transporter 2 (GLUT2), adipose tissue for assessment of glucose transporter 4 (GLUT4) and liver tissue for the assessment of GLUT2, Peroxisome proliferator-activated receptor (PPAR) coactivator-1 (PGC 1 $\alpha$ ), Phospho-insulin receptor, Phosphatidyl inositol- 3 kinase (PI3K) and phospho glycogen synthase kinase (PGSK3 $\beta)$.

\subsection{Biochemical assays}

Oral blood glucose tolerance test was carried out after overnight fasting, a blood droplet was collected from the tail vein directly onto the test strip (baseline) and glucose solution was then administered by oral gavage at a dose of $2.5 \mathrm{~g} / \mathrm{Kg}$. Blood was collected at 30, 60, 90 and 120 min after glucose adminstration. Glucose level was determined using Glucometer (ACCU CHEK Active, Roche Co.). Serum glucose level was determined following the instructions of the reagents obtained from BioMed Diagnostics INC (USA) and the absorbance was measured at 546 $\mathrm{nm}$. Serum insulin concentration was determined following the instructions of the Insulin rat ELISA kit (EMD Millipore, USA), absorbance was measued at $450 \mathrm{~nm}$. Serum triglycerides 
(TG), total cholesterol (TC) and high density lipoprotein-cholesterol (HDL-C) levels were determined by the enzymatic colorimetric method using reagents obtained from BioMed Diagnostics INC (USA), absorbance was measured at $546 \mathrm{~nm}$. Serum low density lipoproteincholesterol (LDL-C) was calculated from TG, TC and HDL-C concentrations using the following equation:

$$
\text { LDL-C }(\mathrm{mg} / \mathrm{dL})=\mathrm{TC}-(\mathrm{HDL}-\mathrm{C})-\mathrm{TG} / 5
$$

Serum alanine amino transferase and aspartate amino transferase were determined using reagents obtained from BioMed Diagnostics INC (USA), absorbance was measured at $340 \mathrm{~nm}$. Urea and Creatinine were determined using reagents obtained from BioMed Diagnostics INC (USA), absorbance was measured at $570 \mathrm{~nm}$ and $510 \mathrm{~nm}$, respectively. Adiponectin rat ELISA kit (Chongqing Biospes Co., Ltd) and Retinol binding protein 4 rat ELISA kit (Chongqing Biospes Co., Ltd) were used for the non-radioactive quantitative quantification of adiponectin and retinol binding protein 4 in rat serum, absorbance was measured at $450 \mathrm{~nm}$.

GLUT2 and GLUT4 assays: Membrane fractions of pancreatic, hepatic and adipose tissues were prepared by a modification of the procedures of Wang et al. [21], tissues were homogenized in $25 \mathrm{mM}$ tris hydrochloride ( $\mathrm{pH} 7.4$ ), $10 \mathrm{mM} \mathrm{MgCl}_{2}$ and $0.25 \mathrm{M}$ sucrose then centrifuged at 720 $\times \mathrm{g}$ for $30 \mathrm{~min}$. The resulting supernatant was centrifuged at $15000 \times \mathrm{g}$ for $90 \mathrm{~min}$. The supernatant was discarded and the pellet was suspended in $25 \mathrm{mM}$ tris hydrochloride, $\mathrm{pH} 7.4$ containing $10 \mathrm{mM} \mathrm{MgC1} 2$ (All steps were performed at $4^{\circ} \mathrm{C}$ ). The pancreatic and hepatic contents of GLUT2 were assayed using GLUT2 rat ELISA kit (Chongqing Biospes Co. Ltd, China), the adipose tissue content of GLUT4 was assayed using GLUT4 rat ELISA kit (Chongqing Biospes Co. Ltd), and absorbance was measured at $450 \mathrm{~nm}$.

Assay of Peroxisome proliferator-activated receptor (PPAR) gamma coactivator-1a (PGC 1a), Phospho-insulin receptor (P-IR), Phosphatidyl inositol- 3 kinase (PI3K) and phospho glycogen synthase kinase $3 \beta$ (P-GSK3ß) in hepatic extract: The hepatic content of PGC $1 \alpha$, PIR, PI3K and P-GSK3 $\beta$ were assayed according the manufacturer's instructions using PGC $1 \alpha$ rat ELISA kit, P-IR rat ELISA kit, PI3K rat ELISA kit, and P-GSK3 $\beta$ rat ELISA kit, respectively, from Chongqing Biospes Co. Ltd,. Absorbance was measured at $450 \mathrm{~nm}$. 


\subsection{Statistical analysis:}

Data were analyzed using SPSS software package version 18.0 (SPSS, Chicago, IL, USA). The data were expressed as mean $\pm \mathrm{SD}$. Comparisons between different groups were made using one way ANOVA. Spearman's rho was used for correlation study. A value of $p<0.05$ was considered as statistically significant difference.

\section{Results}

\subsection{Ferrofluids characterization}

Atomic absorption in a plasma spectrometer was used to determine the iron contents in the SPION-PEG-2000 and SPION-PEG-550. The iron content concentration was $3.47 \mathrm{~g} \mathrm{Fe}_{2} \mathrm{O}_{3} / \mathrm{L}$ and $2.80 \mathrm{~g} \mathrm{Fe}_{2} \mathrm{O}_{3} / \mathrm{L}$ for SPION-PEG-2000 and SPION-PEG-550, respectively.

The particle sizes of the coated and uncoated nanoparticles in the suspension were characterized by DLS, cryoTEM and that of the individual iron oxide nuclei was examined by TEM as shown in Figure 1. Monomodal size distributions were observed for both samples in DLS experiments. Size distribution for the original ferrofluid containing uncoated nanoparticles is shown as reference for SPION-PEG-2000 and SPION-PEG-550 samples (Figure 1(a)). The DLS size distribution of the original ferrofluid shows a peak at $24 \mathrm{~nm}$. Particles were positive charged with Zeta potential average value of $+40 \mathrm{mV}$. After surface modification with bis(phosphonic) poly(ethylene glycol polymer) the hydrodynamic diameters of SPION-PEG2000 and SPION-PEG-550 were $34.2 \pm 10.4 \mathrm{~nm}$ and 30.1 \pm 9.1, respectively. The Zeta potential values were $-18 \mathrm{mV}$ and $-11 \mathrm{mV}$ for SPION-PEG-2000 and SPION-PEG-550, respectively measured in water. CryoTEM image of the nanoparticle suspension (Figure 1(b)) shows only the iron oxide core of the nanoparticles, as the PEG polymer does not give any contrast against the water background. It is observed that iron oxide cores are polynuclear, and they are formed by 17 maghemite nanoparticles grouped in random packing. A size distribution analysis of polynuclear cores from cryoTEM images yielded an average size of $\mathrm{Da}(\mathrm{SD})=23.0(8.1) \mathrm{nm}(\mathrm{N}=$ 210), which is in fair agreement with the DLS size of uncoated nanoparticle sample (see also previous reports $[13,22])$. This clustering process takes place during synthesis of the iron oxide cores before the coating process. TEM examination of individual iron oxide nanoparticles 
showed that they have a rounded shape with and average diameter $\operatorname{DTEм}(S D)=11.2(2.4) \mathrm{nm}$. A histogram of the particle size distribution is shown in Figure 1(c). The nanoparticles have a spinel structure according to XRD patterns. High-resolution images show the crystalline planes and a thin amorphous shell (inset in Figure 1(b)) that could correspond to phosphate ions attached to the surface, because PEG residues do not give any contrast with the carbon film on the microscope grid.

(a)
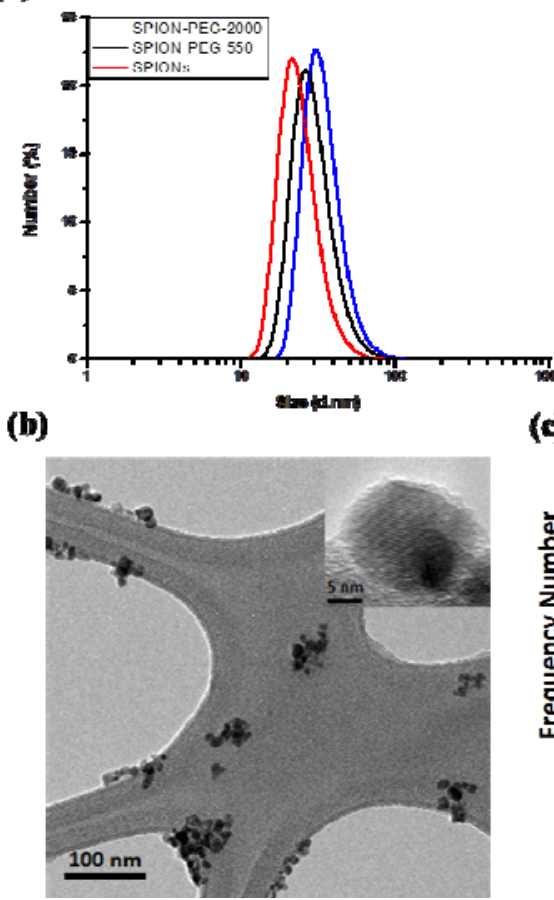

(c)

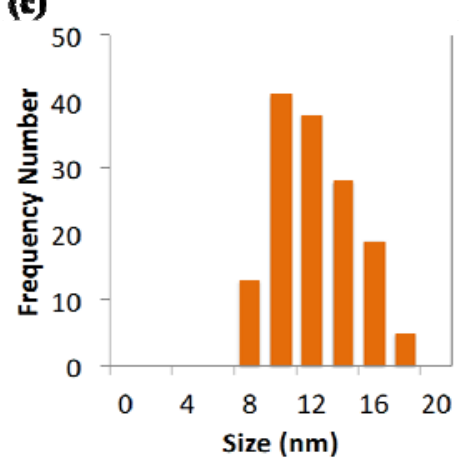

Figure 1: Ferrofluids characterization (a) DLS distribution of hydrodynamic size in the ferrofluids (b) CryoTEM image of the SPION-PEG-2000 sample showing the polynuclear cores of the polymer coated nanoparticles. PEG polymer coating is not visible due to the low contrast of the polymer against the water background. In the inset, a high-resolution TEM image shows the maghemite crystal planes in a single iron oxide nanoparticle. (c) Histogram of the size distribution from TEM images.

\subsection{Glucose homeostasis parameters}

Follow-up of fasting blood glucose level: Fasting blood glucose was followed up for all studied groups during the experiment time (30 days) as shown in Table 1. The untreated diabetic rats had significantly higher FBG level than normal control; values were $382.8 \pm 89.3 \mathrm{mg} / \mathrm{dL}$ and 
$81 \pm 8.3 \mathrm{mg} / \mathrm{dL}$, respectively, at the end of the experiment (day 30). The level of FBG in metformin-treated diabetic rats was decreasing with time. After the first day of treatment, the FBG level was $163.1 \pm 7.4 \mathrm{mg} / \mathrm{dL}$, which is significantly lower than untreated diabetic rats $(361.9 \pm$ $70.94 \mathrm{mg} / \mathrm{dL}$ ), At day 30, FBG level was $135.8 \pm 4.2 \mathrm{mg} / \mathrm{dL}$ for metformin-treated diabetic rats, which is significantly lower than untreated diabetic rats and significantly higher than normal control. Treating diabetic rats with different doses $(22,44$ and $66 \mu$ mole Fe/kg) of SPION-PEG2000 showed time-dependent effect, as the time increases a decrease in FBG level was observed. In addition, a dose-dependent effect was observed until day 14, as increasing the nanoparticle concentrations was associated with a decrease in FBG level. At day 14, FBG level was significantly higher than normal control and significantly lower than untreated diabetic and metformin-treated diabetic rats for the doses $44 \mu$ mole $\mathrm{Fe} / \mathrm{Kg}$ and $66 \mu$ mole $\mathrm{Fe} / \mathrm{Kg}$. At day 16 , FBG level of all doses was significantly lower than untreated diabetic and metformin-treated diabetic rats but still significantly higher than normal control. From day 21, FBG level values showed no significant difference between normal control and SPION-PEG-2000-treated rats in all doses. For instance, at day 30, FBG level values were $86.5 \pm 2.9 \mathrm{mg} / \mathrm{dL}, 87.7 \pm 8 \mathrm{mg} / \mathrm{dL}$, $87.8 \pm 3.8 \mathrm{mg} / \mathrm{dL}$ for the doses 22,44 and $66 \mu$ mole $\mathrm{Fe} / \mathrm{kg}$, respectively. Treating diabetic rats with different doses of SPION-PEG-550 showed time- and dose-dependent effects. After first day of treatment, the FBG level in all doses was significantly higher than normal control but significantly lower than untreated diabetic rats. Also, at day 1, FBG level was significantly lower than metformin-treated diabetic rats only for the doses 44 and $66 \mu$ mole $\mathrm{Fe} / \mathrm{Kg}$. At day 21, only the dose $66 \mu$ mole $\mathrm{Fe} / \mathrm{Kg}$ showed no significant difference from normal control. However, the dose $44 \mu$ mole $\mathrm{Fe} / \mathrm{Kg}$ showed no significant difference from normal control at day 30. The level of FBG at dose $22 \mu$ mole Fe/Kg during the experiment time was significantly higher than normal control and significantly lower than untreated diabetics, and nonsignificantly different from metformin-treated diabetic rats. At day 30, FBG level values were $128 \pm 2 \mathrm{mg} / \mathrm{dL}, 98.1 \pm 6.3 \mathrm{mg} / \mathrm{dL}, 86.9 \pm 11.1 \mathrm{mg} / \mathrm{dL}$ for the doses 22,44 and $66 \mu \mathrm{mole} \mathrm{Fe} / \mathrm{kg}$, respectively. A comparison between SPION-PEG-2000 and SPION-PEG-550 at day 30, for instance, showed that all doses are efficient in lowering the FBG level except the dose 22 $\mu$ mole $\mathrm{Fe} / \mathrm{kg}$ of SPION-PEG-550.

Oral glucose tolerance test (OGTT): OGTT was performed at day 30. Results showed that at the baseline, the untreated diabetic rats had marked significant higher blood glucose level 
than all other groups (Figure 2). The metformin-treated diabetic rats showed significant low blood glucose level compared to untreated diabetic rats, however still significantly higher than control rats. All diabetic rats treated with SPIONs, except at dose of $22 \mu$ mole Fe $/ \mathrm{kg}$, have blood glucose level comparable with that of control rats and significantly lower than untreated diabetic rats and metformin-treated diabetic rats. After glucose load, the blood glucose level peaked after $30 \mathrm{~min}$ and then declined with time to reach near baseline values after $120 \mathrm{~min}$. Values and statistical analyses are shown in Table S1.

The best effect on OGTT was observed in diabetic rats treated with SPION-PEG-2000 at all doses, then SPION-PEG-550 at dose of $66 \mu$ mole Fe/kg. The least effect observed in diabetic rats treated with SPION-PEG-550 at dose of $22 \mu$ mole Fe/kg.

(a)

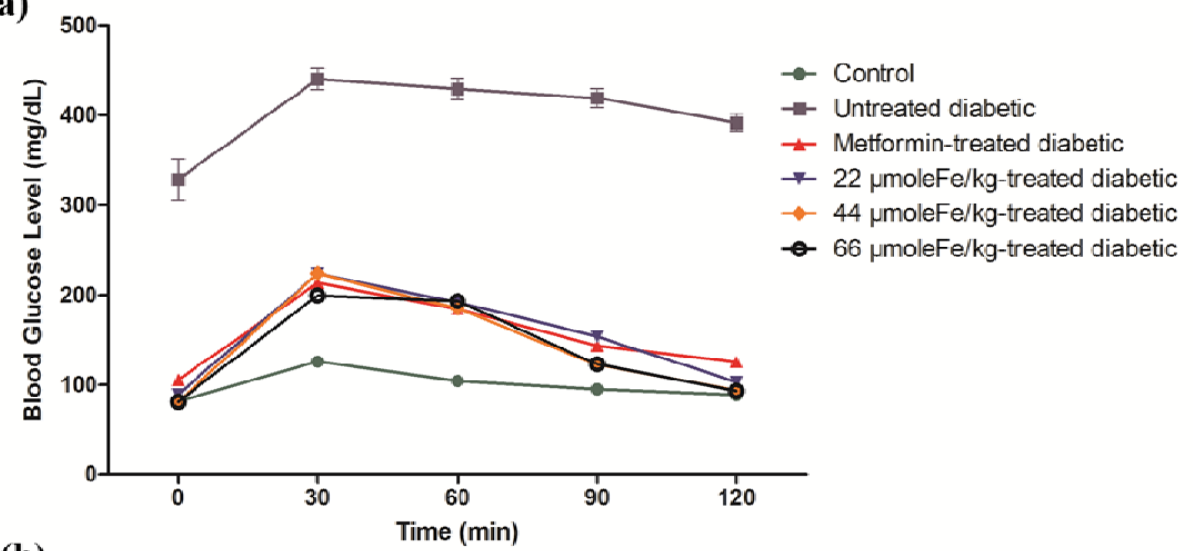

(b)

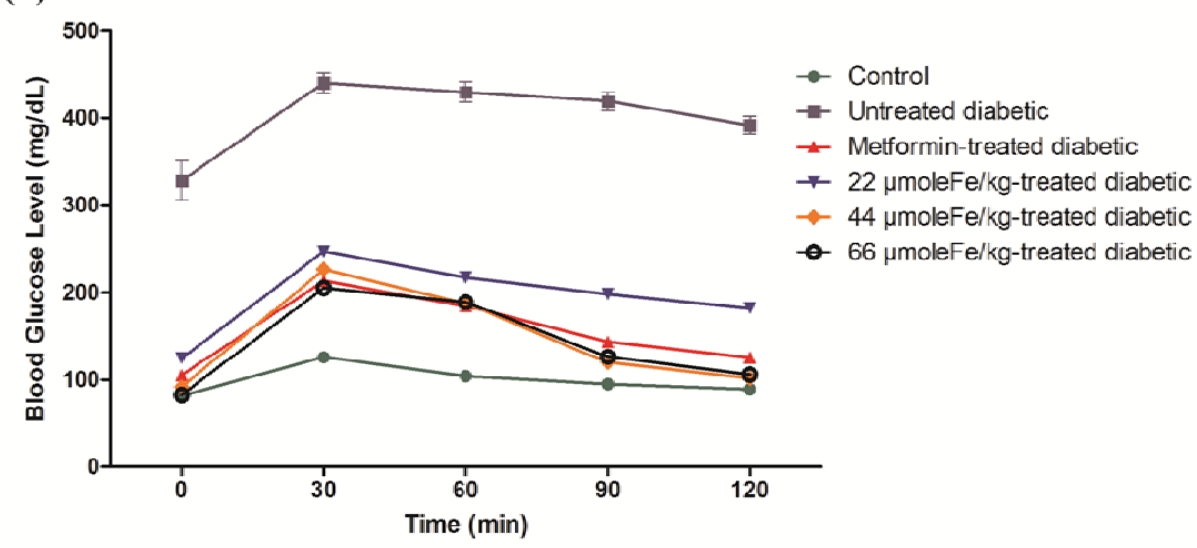

Figure 2: Oral glucose tolerance test in control rats, untreated diabetic rats, metformin-treated diabetic rats, and different doses of SPION-PEG-2000 (a) or SPION-PEG-550 (b). Data are presented as mean $\pm \mathrm{SD}, \mathrm{n}=10$. Values and statistical analysis are shown in Table $\mathrm{S} 1$. 
Table 1: Follow-up of fasting blood glucose level in control normal rats, untreated diabetic rats, metformin-treated diabetic rats and SPIONs-treated diabetic rats during the experiment time.

\begin{tabular}{|c|c|c|c|c|c|c|c|c|c|}
\hline \multicolumn{2}{|c|}{ Day after treatment } & 1 & 7 & 9 & 14 & 16 & 21 & 23 & 30 \\
\hline \multicolumn{2}{|c|}{ Control } & $84.4 \pm 5.2$ & $84.8 \pm 4.7$ & $83.4 \pm 3.1$ & $84.4 \pm 4.4$ & $82.9 \pm 3.7$ & $83.9 \pm 2.9$ & $80.5 \pm 1.6$ & $81 \pm 8.3$ \\
\hline \multicolumn{2}{|c|}{$\begin{array}{l}\text { Untreated diabetic } \\
\text { rats }\end{array}$} & $\begin{array}{c}361.9 \pm 70.94 \\
*\end{array}$ & $\begin{array}{c}375.2 \pm 41.3 \\
*\end{array}$ & $\begin{array}{c}365.5 \pm 51.4 \\
* \\
\end{array}$ & $\begin{array}{c}373 \pm 51.1 \\
* \\
\end{array}$ & $\begin{array}{c}365.5 \pm 51.4 \\
* \\
\end{array}$ & $\begin{array}{c}361.7 \pm 53.5 \\
* \\
\end{array}$ & $\begin{array}{c}375.2 \pm 40.8 \\
* \\
\end{array}$ & $\begin{array}{c}382.8 \pm 89.3 \\
*\end{array}$ \\
\hline \multicolumn{2}{|c|}{$\begin{array}{c}\text { Metformin treated } \\
\text { diabetic rats } \\
(200 \mathrm{mg} / \mathrm{kg}) \\
\end{array}$} & $\begin{array}{c}163.1 \pm 7.4 \\
* \#\end{array}$ & $\begin{array}{c}153.9 \pm 6.5 \\
* \#\end{array}$ & $\begin{array}{c}149.7 \pm 10.0 \\
* \#\end{array}$ & $\begin{array}{c}146.4 \pm 6.1 \\
* \#\end{array}$ & $\begin{array}{c}143.6 \pm 4.3 \\
* \#\end{array}$ & $\begin{array}{c}139.9 \pm 6.9 \\
* \#\end{array}$ & $\begin{array}{c}134.9 \pm 5.2 \\
* \#\end{array}$ & $\begin{array}{c}135.8 \pm 4.2 \\
* \#\end{array}$ \\
\hline \multirow{3}{*}{$\begin{array}{c}\text { SPION- } \\
\text { PEG } \\
\text { 2000- } \\
\text { treated } \\
\text { diabetic } \\
\text { rats }\end{array}$} & $\begin{array}{c}22 \mu \mathrm{mol} \\
\mathrm{Fe} / \mathrm{kg}\end{array}$ & $\begin{array}{c}136.3 \pm 5.8 \\
* \#+\end{array}$ & $\begin{array}{l}148.9 \pm 6.1 \\
* \#\end{array}$ & $\begin{array}{c}131 \pm 3.3 \\
* \#+\end{array}$ & $\begin{array}{l}142.5 \pm 2.8 \\
* \#\end{array}$ & $\begin{array}{c}106 \pm 3.2 \\
* \#+\end{array}$ & $\begin{array}{c}91 \pm 3.2 \\
\#+\end{array}$ & $\begin{array}{c}84.9 \pm 4.7 \\
\#+\end{array}$ & $\begin{array}{c}86.5 \pm 2.9 \\
\#+\end{array}$ \\
\hline & $\begin{array}{c}44 \mu \mathrm{mol} \\
\mathrm{Fe} / \mathrm{kg}\end{array}$ & $\begin{array}{c}114.2 \pm 10.11 \\
* \#+\mathrm{a}\end{array}$ & $\begin{array}{c}130.2 \pm 5.2 \\
* \#+\mathrm{a}\end{array}$ & $\begin{array}{c}108.3 \pm 6.0 \\
* \#+\mathrm{a} \\
\end{array}$ & $\begin{array}{c}127.4 \pm 5.2 \\
* \#+\end{array}$ & $\begin{array}{c}98.9 \pm 7.2 \\
* \#+\end{array}$ & $\begin{array}{c}91.4 \pm 4.7 \\
\#+\end{array}$ & $\begin{array}{c}86.1 \pm 5.7 \\
\#+\end{array}$ & $\begin{array}{c}87.7 \pm 8 \\
\#+\end{array}$ \\
\hline & $\begin{array}{c}66 \mu \mathrm{mol} \\
\mathrm{Fe} / \mathrm{kg}\end{array}$ & $\begin{array}{c}103.7 \pm 4.4 \\
* \#+\mathrm{a}\end{array}$ & $\begin{array}{c}123.3 \pm 5.4 \\
* \#+\mathrm{a}\end{array}$ & $\begin{array}{c}98.6 \pm 5.2 \\
* \#+a\end{array}$ & $\begin{array}{c}119.9 \pm 6.0 \\
* \#+\mathrm{a}\end{array}$ & $\begin{array}{c}95.6 \pm 4.7 \\
* \#+\end{array}$ & $\begin{array}{c}89.3 \pm 5.5 \\
\#+\end{array}$ & $\begin{array}{c}85.1 \pm 6.1 \\
\#+\end{array}$ & $\begin{array}{c}87.8 \pm 3.8 \\
\#+\end{array}$ \\
\hline \multirow{3}{*}{$\begin{array}{c}\text { SPION- } \\
\text { PEG } \\
550- \\
\text { treated } \\
\text { diabetic } \\
\text { rats }\end{array}$} & $\begin{array}{c}22 \mu \mathrm{mol} \\
\mathrm{Fe} / \mathrm{kg}\end{array}$ & $\begin{array}{c}145.3 \pm 4.8 \\
* \#\end{array}$ & $\begin{array}{c}162.1 \pm 6.7 \\
* \#\end{array}$ & $\begin{array}{c}138.8 \pm 5.6 \\
* \#\end{array}$ & $\begin{array}{c}156.7 \pm 5.7 \\
* \#\end{array}$ & $\begin{array}{c}133.3 \pm 4.5 \\
* \# \$\end{array}$ & $\begin{array}{c}131.5 \pm 5.2 \\
* \# \$\end{array}$ & $\begin{array}{c}125.4 \pm 3.6 \\
* \# \$\end{array}$ & $\begin{array}{c}128 \pm 2 \\
* \# \$\end{array}$ \\
\hline & $\begin{array}{c}44 \mu \mathrm{mol} \\
\mathrm{Fe} / \mathrm{kg}\end{array}$ & $\begin{array}{c}130.9 \pm 5.2 \\
* \#+\end{array}$ & $\begin{array}{c}144 \pm 6.6 \\
* \# a \$\end{array}$ & $\begin{array}{c}125.9 \pm 2.6 \\
* \#+\$\end{array}$ & $\begin{array}{c}141.9 \pm 5.4 \\
* \#\end{array}$ & $\begin{array}{c}114.1 \pm 7.4 \\
* \#+\mathrm{a} \\
\end{array}$ & $\begin{array}{c}100.6 \pm 3.8 \\
* \#+\mathrm{a}\end{array}$ & $\begin{array}{c}96.4 \pm 7.3 \\
* \# \mathrm{a}\end{array}$ & $\begin{array}{c}98.1 \pm 6.3 \\
\#+a\end{array}$ \\
\hline & $\begin{array}{c}\text { 66 } \mathrm{mmol} \\
\mathrm{Fe} / \mathrm{kg}\end{array}$ & $\begin{array}{c}121.7 \pm 9.0 \\
* \#+\mathrm{a}\end{array}$ & $\begin{array}{c}129.9 \pm 7.2 \\
* \#+\mathrm{ab}\end{array}$ & $\begin{array}{c}119.6 \pm 8.7 \\
* \#+a \$\end{array}$ & $\begin{array}{c}126 \pm 5.6 \\
* \#+a b\end{array}$ & $\begin{array}{c}103.8 \pm 3.7 \\
* \#+\mathrm{a}\end{array}$ & $\begin{array}{c}87.3 \pm 5.1 \\
\#+a\end{array}$ & $\begin{array}{c}84.2 \pm 6.7 \\
\#+a\end{array}$ & $\begin{array}{c}86.9 \pm 11.1 \\
\#+\mathrm{a}\end{array}$ \\
\hline
\end{tabular}

Data presented as Mean $\pm S D(n=10)$

*: significantly different from control rats by ANOVA $(p<0.05)$

\#: significantly different from untreated diabetic rats by ANOVA $(p<0.05)$

+ : significantly different from metformin-treated rats by ANOVA $(p<0.05)$

a: significantly different from diabetic rats treated with the $22 \mu$ mole Fe/kg SPION-PEG by ANOVA ( $p<0.05)$

$b$ : significantly different from diabetic rats treated with the $44 \mu \mathrm{mole}$ Fe $/ \mathrm{kg}$ SPION-PEG by ANOVA $(p<0.05)$

\$: significantly different from rats treated with the SPION-PEG2000 at the corresponding dose by $t$-test $(p<0.05)$ 
Insulin level: The untreated diabetic rats had marked significant higher insulin levels than control rats and all other treated groups. The diabetic rats treated with SPIONs had significantly low insulin levels compared to untreated diabetic rats. The decline in insulin level appeared to be dose-dependent in both types of SPIONs used.

In comparison with metformin-treated rats, SPION-PEG-2000-treated rats had high insulin level at all doses, while SPION-PEG-550-treated rats had high insulin level at $22 \mu$ mole $\mathrm{Fe} / \mathrm{kg}$ and low level of insulin at higher doses (44 and $66 \mu \mathrm{mol} \mathrm{Fe} / \mathrm{kg}$ ). Diabetic rats treated with SPION-PEG-550 had a lower insulin level than the rats treated with SPION-PEG-2000, the decrease was significant at the doses of $44 \mu \mathrm{mol} \mathrm{Fe} / \mathrm{kg}$ and $66 \mu \mathrm{mol} \mathrm{Fe} / \mathrm{kg}$ (Table S2).

The insulin resistance index calculated as HOMA-IR showed a higher significant value in untreated diabetic rats than control rats and all other treated diabetic groups. Metformin-treated diabetic rats had significantly lower HOMA-IR level than untreated diabetic rats but still significantly higher than control rats. All diabetic rats treated with different doses of SPIONs had significantly lower HOMA-IR level than untreated rats in a dose-dependent manner. In addition, no significant difference from control rats was observed except for the dose $22 \mu \mathrm{mol} \mathrm{Fe} / \mathrm{kg}$ in both SPIONs used.

SPION-PEG-2000-treated diabetic rats at 44 and $66 \mu \mathrm{mol} \mathrm{Fe} / \mathrm{kg}$ and SPION-PEG-550treated diabetic rats at the dose $66 \mu \mathrm{mol} \mathrm{Fe} / \mathrm{kg}$ had significantly lower HOMA-IR than metformin-treated rats. No significant difference observed in HOMA-IR level between SPIONPEG-2000- and SPION-PEG-550-treated groups (Table S2).

\subsection{Lipid profile}

Untreated diabetic rats had marked significant higher TG and TC levels than control rats and all treated groups. A dose-dependent manner was observed in SPIONs-treated rats, as increasing the dose was associated with a decrease in TG and TC levels (Table S3).

SPION-PEG-550-treated diabetic rats had high TG level compared to SPION-PEG-2000treated diabetic rats at corresponding doses. The metformin-treated diabetic rats had significantly 
lower TG level than untreated rats and no significant difference from control rats. In contrast, TC level is completely normalized in SPION-PEG-550-treated diabetic rats that showed a lower TC level than SPION-PEG-2000 at corresponding doses. The metformin-treated diabetic rats had significantly lower TC level than untreated diabetic rats, however still significantly higher than control rats.

All groups (untreated and treated-diabetic rats) had significantly lower HDL-C level than control rats. Metformin-treated diabetic rats did not show significant difference from untreated rats. In SPIONs-treated diabetic rats, increasing the dose was associated with an increase in the HDL-C level. Rats treated with SPION-PEG-2000 and SPION-PEG-500 at a dose of $66 \mu \mathrm{mol}$ $\mathrm{Fe} / \mathrm{kg}$ showed significant higher HDL-C level than untreated rats. No significant difference was observed in HDL-C level between rats treated with SPION-PEG-550 and SPION-PEG-2000 except at the dose $22 \mu \mathrm{mol} \mathrm{Fe} / \mathrm{kg}$.

The untreated diabetic rats had significant high LDL-C level compared to control rats and all treated groups. The diabetic rats treated with metformin had significantly higher LDL-C level than control rats and no significant difference from untreated rats. The diabetic rats treated with SPIONs showed significantly low LDL-C compared to untreated rats in a dose-dependent manner.

SPION-PEG-550-treated diabetic rats had significantly lower LDL-C level than SPIONPEG-2000-treated diabetic rats at the corresponding doses.

\subsection{Liver function tests}

The untreated diabetic rats had significantly higher ALT activity than control rats and all treated groups (Table S4). Metformin-treated diabetic rats were not significantly different from control rats. In contrast, all SPIONs-treated groups had significantly higher ALT activity than control and metformin-treated rats. SPION-PEG-550-treated rats with the exception at dose of $44 \mu \mathrm{mol} \mathrm{Fe} / \mathrm{kg}$ had significantly lower ALT activity than SPION-PEG-2000-treated rats at corresponding doses.

Both untreated diabetic and treated diabetic rats had significantly higher AST activity than control rats. Metformin-treated diabetic rats were not significantly different from untreated 
diabetic rats. SPION-PEG-2000- or SPION-PEG-550-treated diabetic rats at the dose of 22 $\mu \mathrm{mol} \mathrm{Fe} / \mathrm{kg}$ showed significant decline in AST activity compared to untreated rats or metformin-treated diabetic rats. In contrast, treating diabetic rats with higher doses $(44 \mu \mathrm{mol}$ $\mathrm{Fe} / \mathrm{kg}$ and $66 \mu \mathrm{mol} \mathrm{Fe} / \mathrm{kg}$ ) of SPIONs showed significantly and markedly increases in serum AST activity compared to untreated rats or metformin treated rats. The rats treated with SPIONPEG-550 at dose of $66 \mu \mathrm{mol} \mathrm{Fe} / \mathrm{kg}$ showed significantly higher AST activity than rats treated with the corresponding dose of SPION-PEG-2000 (Table S4).

\subsection{Kidney function tests}

The untreated diabetic rats had significantly high urea level compared to control rats and all treated groups. Metformin-treated rats had significantly lower urea level than untreated diabetic rats but still had significantly higher level than control rats. SPIONs-treated diabetic rats had normal urea levels, which were significantly lower than untreated and metformintreated rats (Table S4).

SPION-PEG-550-treated rats, with the exception of the dose $66 \mu \mathrm{mol} \mathrm{Fe} / \mathrm{kg}$, had significantly higher urea level than SPION-PEG-2000-treated rats at corresponding doses.

The untreated diabetic rats had significantly higher serum creatinine level than control rats. Metformin-treated rats had significantly lower creatinine level than untreated diabetic rats with no significant difference compared to control rats. In SPIONs-treated diabetic rats, increasing the dose was associated with an increase in the serum creatinine level. SPION-PEG2000-treated diabetic rats showed significantly higher serum creatinine level than control and metformin-treated diabetic rats. SPION-PEG-550-treated diabetic rats had significantly lower serum creatinine level than untreated rats, but had significantly higher creatinine level than control and metformin-treated rats at a dose of $66 \mu \mathrm{mol} \mathrm{Fe} / \mathrm{kg}$. SPION-PEG-550-treated diabetic rats had significantly lower creatinine level than SPION-PEG-2000-treated diabetic rats at corresponding doses (Table S4).

\subsection{Serum Adiponectin}

The untreated diabetic rats had significantly lower adiponectin level than control rats and all other treated groups. Metformin-treated diabetic rats had significantly lower adiponectin 
level than control rats. All SPIONs-treated diabetic rats had significantly higher adiponectin level than untreated rats but significantly lower than control and metformin-treated rats. SPION-PEG-550-treated diabetic rats had significantly higher adiponectin level than SPIONPEG-2000-treated diabetic rats at corresponding doses (Table S5).

\subsection{Serum Retinol binding protein 4}

The untreated diabetic rats had significantly higher serum level of RBP4 than control rats and all other treated groups. Metformin- and SPIONs-treated diabetic rats had significantly higher RBP4 level than control rats. No significant difference in the level of RBP4 between the SPIONs-treated and metformin-treated diabetic rats was observed (Table S5).

\subsection{Hepatic and pancreatic content of GLUT2 and adipose tissue GLUT4}

The untreated diabetic rats showed significantly lower hepatic and pancreatic GLUT2 content than control rats. Metformin and SPIONs treatments significantly increased the hepatic and pancreatic GLUT2 content compared to untreated diabetic rats but the level still significantly lower than control rats, except the dose $44 \mu \mathrm{mol} \mathrm{Fe} / \mathrm{kg}$ for both SPIONs, which had lower pancreatic GLUT 2 values but not significantly different from control (Table S6).

The rats treated with different doses of SPION-PEG-550, with the exception of the dose of $22 \mu \mathrm{mol} \mathrm{Fe} / \mathrm{kg}$, had significantly higher hepatic GLUT2 content than rats treated with SPION-PEG-2000 at corresponding doses. In contrast, no significant differences in the pancreatic content of GLUT2 were observed between the two types of SPIONs.

The untreated diabetic rats had significantly lower GLUT4 content than control rats and all other treated groups. GLUT 4 content values in metformin-treated diabetic rats were not significantly different from control rats. SPIONs-treated rats had significantly lower GLUT4 content than control rats with the exception of rats treated with SPION-PEG-550 at doses of 44 $\mu \mathrm{mol} \mathrm{Fe} / \mathrm{kg}$ and $66 \mu \mathrm{mol} \mathrm{Fe} / \mathrm{kg}$ (Table S6).

SPION-PEG-2000-treated diabetic rats with different doses had significantly lower GLUT4 content than metformin-treated diabetic rats, however, SPION-PEG-550-treated diabetic rats with different doses showed no significant difference from metformin-treated rats. 
SPION-PEG-550-treated rats with the exception of the dose $22 \mu \mathrm{mol} \mathrm{Fe} / \mathrm{kg}$ had significantly higher GLUT4 content than SPION-PEG-2000-treated rats at corresponding doses (Table S6).

\subsection{Hepatic content of phospho-insulin receptor and phosphatidyl inositol- 3 kinase}

The untreated diabetic rats had significantly lower P-IR and PI3K contents than control rats and other treated groups. Metformin- and SPIONs-treated diabetic rats had significantly lower P-IR and PI3K contents than control rats. SPIONs-treated diabetic rats had significantly higher P-IR and PI3K contents, except rats treated with $22 \mu \mathrm{mol} \mathrm{Fe} / \mathrm{kg}$ SPION-PEG-2000, than untreated rats in a dose-dependent manner (Figure 3).

The diabetic rats treated with different doses of SPIONs had significantly lower P-IR content than metformin-treated diabetic rats (Figure 3(a)). In contrast, rats treated with different doses of SPION-PEG-2000 with the exception of the dose $66 \mu \mathrm{mol} \mathrm{Fe} / \mathrm{kg}$ had significantly lower PI3K content than metformin-treated diabetic rats. Rats treated with SPION-PEG-550 at $22 \mu \mathrm{mol} \mathrm{Fe} / \mathrm{kg}$ had significantly lower PI3K content than metformin-treated diabetic rats, while at a dose of $66 \mu \mathrm{mol} \mathrm{Fe} / \mathrm{kg}$, a significant higher PI3K content than metformin-treated diabetic rats was observed (Figure 3(b)).

No significant difference in P-IR content between SPION-PEG-2000 and SPION-PEG550-treated groups was observed, while SPION-PEG-550-treated diabetic rats with the exception at the dose of $22 \mu \mathrm{mol} \mathrm{Fe} / \mathrm{kg}$ had significantly higher PI3K content than SPIONPEG-2000-treated diabetic rats at corresponding doses. 

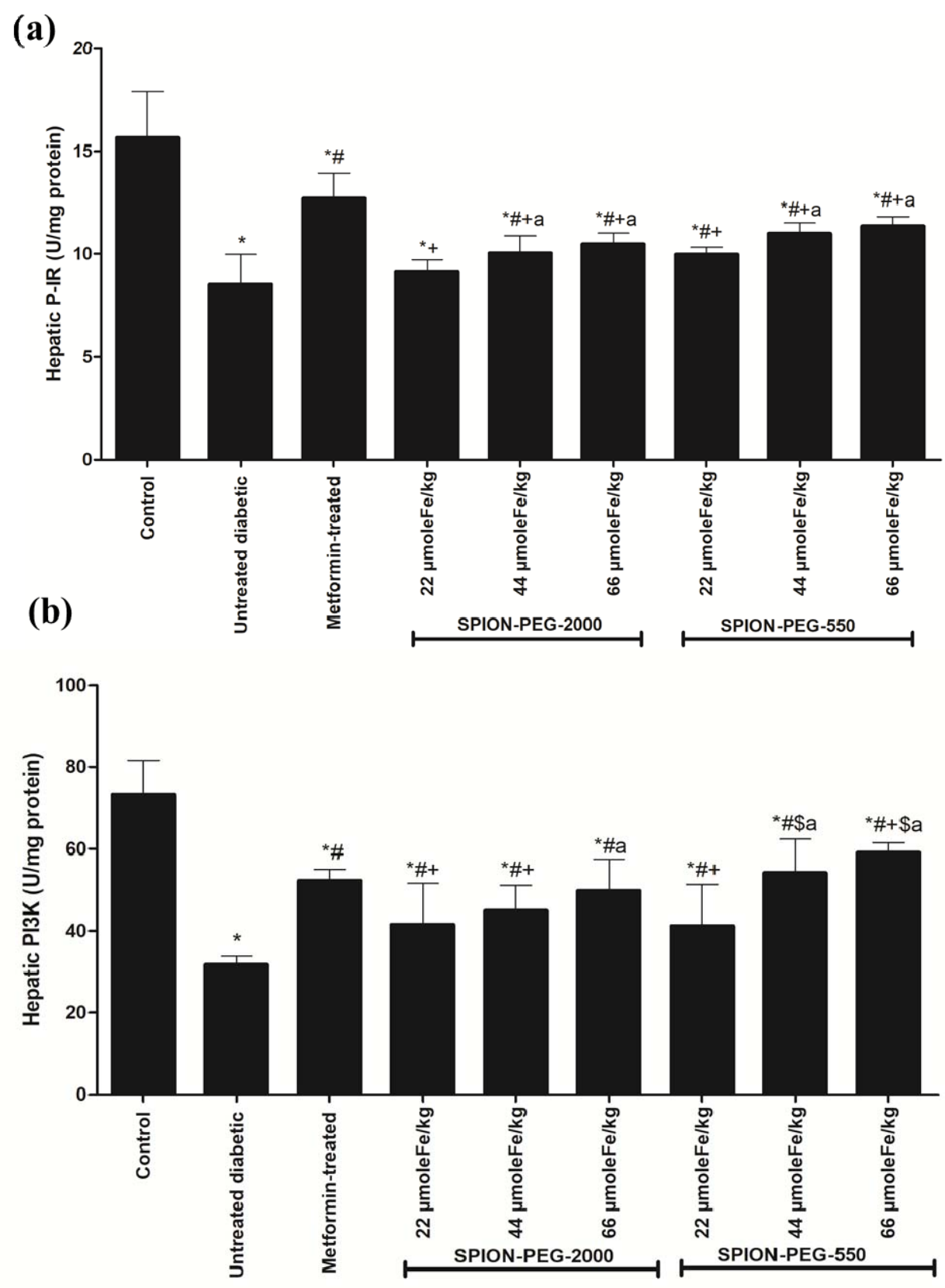

Figure 3: Hepatic content of Phospho-insulin receptor (a) P-IR (b) PI3K. *: significantly different from control rats by ANOVA $(\mathrm{p}<0.05)$, \#: significantly different from untreated diabetic rats by ANOVA $(\mathrm{p}<0.05),+$ : significantly different from metformin-treated rats by ANOVA $(p<0.05)$, a: significantly different from diabetic rats treated with the $22 \mu$ mole $\mathrm{Fe} / \mathrm{kg}$ SPION-PEG by ANOVA $(\mathrm{p}<0.05), \$$ : significantly different from rats treated with the SPIONPEG2000 at the corresponding dose by t-test $(\mathrm{p}<0.05)$. 


\subsection{Hepatic content of phospho- glycogen synthase kinase 3ß}

Untreated diabetic rats had significantly lower P-GSK3 $\beta$ content than control rats. Metformin-treated diabetic rats had significantly lower P-GSK3 $\beta$ content than control rats and no significant difference from untreated rats. SPION-PEG-2000-treated diabetic rats, with the exception of the dose $22 \mu \mathrm{mol} \mathrm{Fe} / \mathrm{kg}$, had significantly higher P-GSK3 $\beta$ content than untreated and metformin-treated diabetic rats. However, SPION-PEG-550-treated diabetic rats had significantly higher content of P-GSK3 $\beta$ than untreated rats at all doses and significantly higher than metformin-treated diabetic rats at doses $44 \mu \mathrm{mol} \mathrm{Fe} / \mathrm{kg}$ and $66 \mu \mathrm{mol} \mathrm{Fe} / \mathrm{kg}$ (Figure 4).

The hepatic content of P-GSK3 $\beta$ was completely normalized at the high doses (44 $\mu$ mol $\mathrm{Fe} / \mathrm{kg}$ and $66 \mu \mathrm{mol} \mathrm{Fe} / \mathrm{kg}$ ). There was no significant difference in P-GSK3 $\beta$ content between SPION-PEG-550- and SPION-PEG-2000-treated diabetic groups except at the dose of $44 \mu \mathrm{mol}$ $\mathrm{Fe} / \mathrm{Kg}$ (Figure 4).

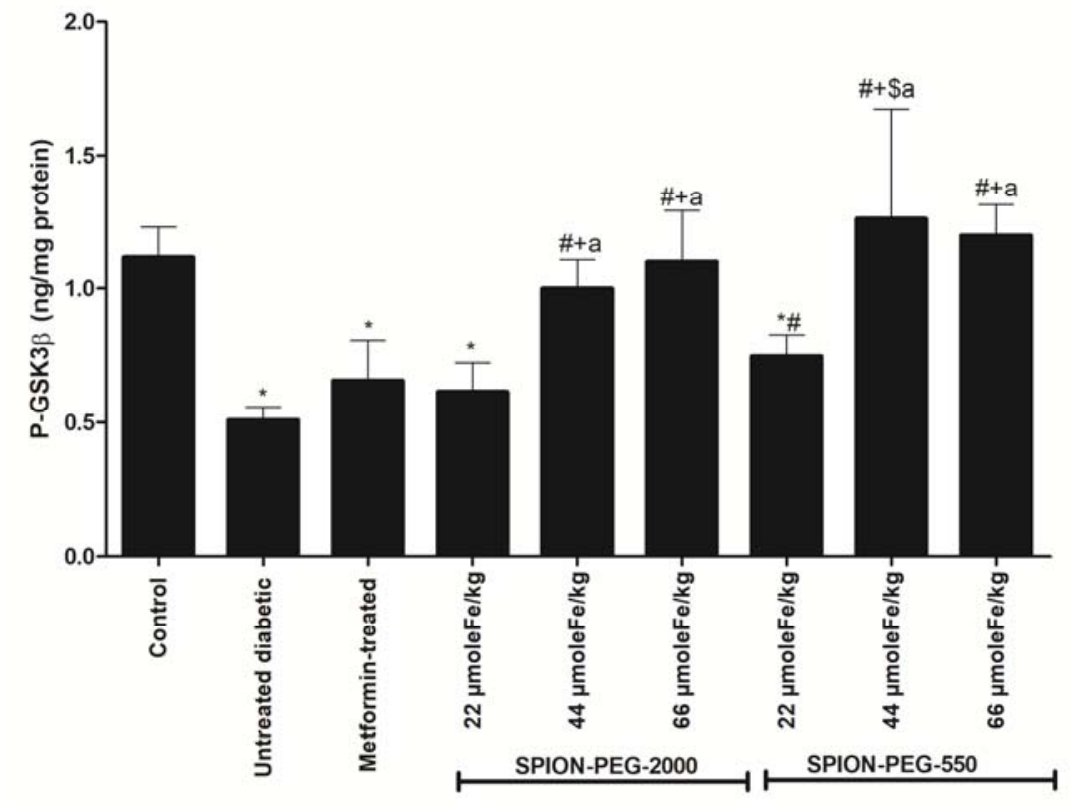

Figure 4: Hepatic content of phospho- glycogen synthase kinase $3 \beta . *$ : significantly different from control rats by ANOVA $(\mathrm{p}<0.05)$, \#: significantly different from untreated diabetic rats by ANOVA $(\mathrm{p}<0.05),+$ : significantly different from metformin-treated rats by ANOVA $(\mathrm{p}<0.05)$, a: significantly different from diabetic rats treated with the $22 \mu$ mole Fe/kg SPION-PEG by ANOVA $(p<0.05), \$$ : significantly different from rats treated with the SPION-PEG2000 at the corresponding dose by t-test $(\mathrm{p}<0.05)$. 


\subsection{Hepatic peroxisome proliferator-activated receptor gamma coactivator 1- alpha content}

The hepatic PGC-1 $\alpha$ content was significantly lower in the untreated rats than control rats. Metformin-treated diabetic rats had significantly lower PGC-1 $\alpha$ than control rats. All SPIONs-treated diabetic rats were significantly higher in PGC-1 $\alpha$ content than metformintreated diabetic rats in a dose-dependent manner. Also, they were significantly higher than the untreated rats at doses $44 \mu \mathrm{mol} \mathrm{Fe} / \mathrm{kg}$ and $66 \mu \mathrm{mol} \mathrm{Fe} / \mathrm{kg}$ (Figure 5).

SPION-PEG-550-treated diabetic rats, with the exception of the dose of $22 \mu \mathrm{mol} \mathrm{Fe} / \mathrm{kg}$, had significantly lower PGC-1 $\alpha$ content than SPION-PEG-2000-treated diabetic rats at corresponding doses (Figure 5).

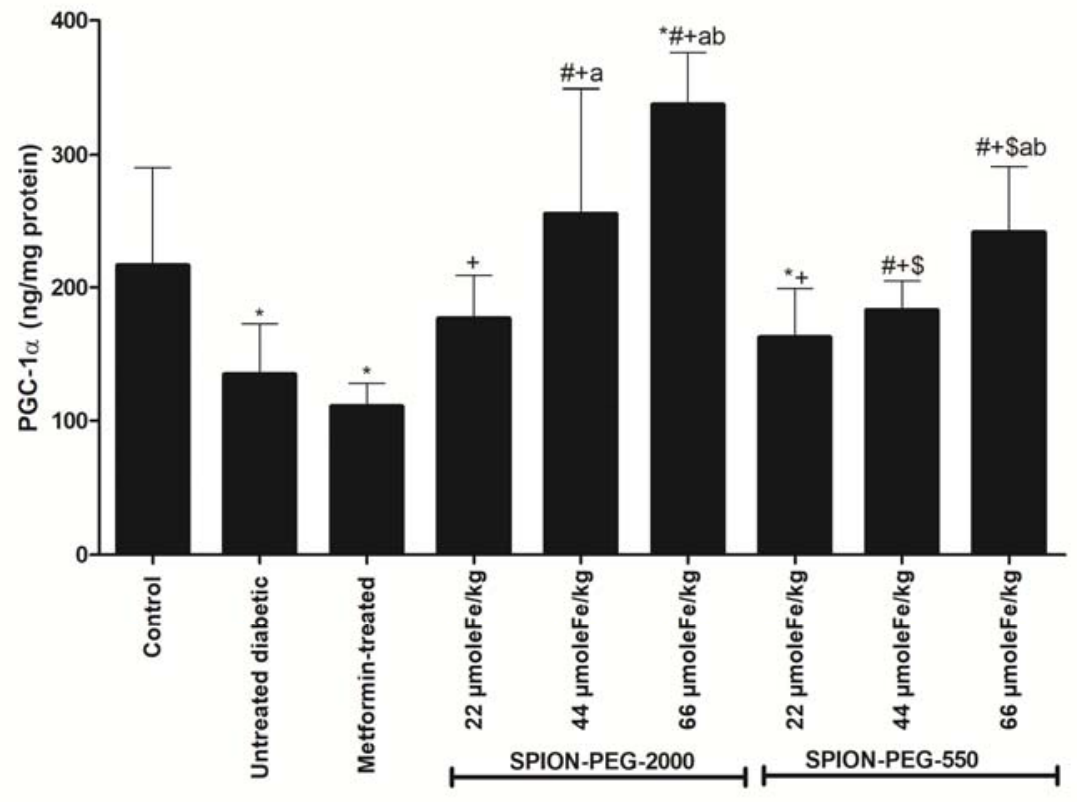

Figure 5: Hepatic content of peroxisome proliferator-activated receptor gamma coactivator 1alpha content. *: significantly different from control rats by ANOVA $(p<0.05)$, \#: significantly different from untreated diabetic rats by ANOVA $(\mathrm{p}<0.05),+$ : significantly different from metformin-treated rats by ANOVA $(\mathrm{p}<0.05)$, a: significantly different from diabetic rats treated with the $22 \mu$ mole Fe/kg SPION-PEG by ANOVA $(p<0.05)$, $b$ : significantly different from diabetic rats treated with the $44 \mu$ mole Fe/kg SPION-PEG by ANOVA $(p<0.05), \$$ : significantly different from rats treated with the SPION-PEG2000 at the corresponding dose by t-test $(\mathrm{p}<0.05)$. 


\subsection{Correlation studies:}

The statistical analysis using Spearman's rho correlation reveals that hepatic content of PGC1 $\alpha$ is inversely correlated with: fasting blood glucose level $(r=-0.305, p=0.018$, Figure S3(a)) and HOMA-IR ( $r=-0.301, p=0.019$, Figure S3(b)) and direct correlated with hepatic content of PI3K (r=0.349, p=0.006, Figure S3(c)).

\section{Discussion}

In the present study we evaluated the possible anti-diabetic effect of SPIONs on streptozotocin-induced diabetic rats and compared their effect to metformin treatment.

A high fasting insulin level was evident in our diabetes model, this could be elucidated as the administration of HFD in our animal model for 4 weeks exacerbated insulin resistance and even after the administration of low dose of STZ. Consequently, insulin is unable to act properly on resistant tissues, resulting in poor glucose disposal. Therefore, pancreatic $\beta$-cells initially compensated for insulin resistance by increasing insulin secretion until pancreatic $\beta$ cells exhaustion and apoptosis could occur. Multiple organs including liver, adipose tissues, and skeletal muscle contribute to the development of peripheral insulin resistance [23].

The disturbed glucose homeostasis in diabetic rat model was associated with abnormalities in the lipid profile (Table S3). These derangements may be a cause or a consequence of the diabetic state and insulin resistance $[24,25]$. Dyslipidemia observed in the diabetic rats was associated with elevated hepatic enzymes (AST and ALT), which indicated hepatocytes inflammation that could be due to the accumulation of fats and the induction of fatty liver [26].

Diabetic rat model showed imbalanced adipocytokines production as the adiponectin level was declined to be about $44 \%$ of the normal values while the RBP4 level was doubled (Table S5). The high fat diet endorses the expansion of the adipose tissue, which is tightly associated with adipose inflammation and a distorted adipocytokine profile, representing dysfunctional adipocytes [27]. The adipose-derived serum RBP4 may represent a glucose sensor that regulates 
systemic glucose metabolism in response to decreased intracellular glucose concentrations. RBP4 is shown to be up-regulated in several insulin-resistant mouse models and in subjects with insulin resistance or T2DM [28].

These shifts in glucose homeostasis were associated with changes in the peripheral sensing of glucose in muscle and adipose tissues. Peripheral glucose sensing starts at insulin receptor and ends with the translocation of glucose transporters to the plasma membrane of the cell [29]. Diabetic rat model showed impaired glucose sensing and transport in the pancreas, liver and adipose tissues as a decline in the pancreatic and hepatic contents of GLUT2 and adipose tissues content of GLUT4 was observed.

At insulin signaling level, diabetic rat model showed severe derangements in the insulin signaling pathways in hepatocytes as severe decline in active P-IR and PI3K was detected. Activation of PI3K by phosphorylated insulin receptor substrate1 (IRS-1) leads to activation of protein kinase $\mathrm{B} / \mathrm{Akt}$, which is a central intermediate for many of the metabolic and growth actions of insulin [30]. Glycogen synthase kinase $3 \beta$ is one of the main substrates of active Akt. It has been shown that Akt responsible for the inactivation of GSK3 $\beta$ through its phosphorylation, a process that leads to the activation of glycogen synthase. In the present diabetic model, the level of inactive phosphorylated GSK3 $\beta$ was declined that mean increased un-phosphorylated active form which responsible for phosphorylating and inhibition of glycogen synthase. Insulin is known to down-regulate insulin receptor protein by inducing its degradation [31] and by inhibiting its gene transcription [32]. So, the increased insulin level may partially interpret the observed decline in P-IR level.

Defects in mitochondrial number, function, and morphology were proven to be associated with animal models of T2DM as well as humans [33]. One of the main regulators of mitochondrial biogenesis and function is PGC-1 $\alpha$. It has also been hypothesized that a close connection exists among PGC-1 $\alpha$, insulin sensitivity, and T2DM, which is most likely related to the essential roles of PGC-1 $\alpha$ in mitochondrial biogenesis and glucose/fatty acid metabolism. It has been also reported that PGC-1 $\alpha$ induces the expression of mitochondrial transcription factor A (Tfam) [34]. The present data indicated severe down-regulation of PGC-1 $\alpha$ in the hepatic tissues of diabetic rat model that may imply impaired mitochondrial biogenesis and/or function. 
From the previous discussion, it's clear that the present rat model of diabetes showed many human diabetic manifestations of glucose and lipid homeostasis, adipocytokines, glucose sensing and insulin signaling. We use this model to explore the effect of weekly injected different doses of SPIONs (22, 44 and $66 \mu \mathrm{mol} \mathrm{Fe} / \mathrm{kg}$ ) with different PEG lengths (550 and $2000 \mathrm{Da})$ on the multiple derangements associated with diabetic rat model through investigating their influence on the previously mentioned factors, in comparison to metformin at daily dose of $200 \mathrm{mg} / \mathrm{kg}$.

The current study showed that SPIONs had significant ameliorating effects on the different pathways involved in diabetes pathogenesis in diabetic rat model, however, there were some discrepancies concerning the dose, the PEG chain length, and the extent of the effects compared to metformin.

The present study confirms the anti-diabetic effects of metformin in the diabetic rats.

Regarding SPIONs, to our knowledge, this is the first study that explores the anti-diabetic effects of SPIONs on diabetic model. Surprisingly, SPIONs treatments lowered FBG in diabetic rats from the first day of treatment, reaching to normal values at the end of the experiment time. Also, the diabetic rats treated with SPIONs had significantly lower insulin levels and HOMAIR than untreated rats and the decline appear to be dose-dependent with both types of SPIONs. These hypoglycemic effects of SPIONs were confirmed by OGTT which indicated a marked correction of glucose tolerance in the diabetic rats to the same extent as metformin.

The exact molecular mechanism(s) involved in the influence of SPIONs on insulin sensitivity is unclear; consequently, the probable effect on peripheral glucose sensing and components of insulin signaling in this mechanism was explored in the current study. Results showed that SPIONs significantly ameliorate the hepatic and pancreatic level of GLUT2 and adipose tissues level of GLUT4. These effects are associated with significant increase in the active components of insulin signaling pathway including; P-IR and PI3K. This activation of the upstream components of insulin signaling resulted in a significant elevation in the inactive P-GSK3 $\beta$ and subsequent activation of glycogen synthesis, inhibition of gluconeogenesis and amelioration of insulin sensitivity. 
The anti-diabetic effects of SPIONs may be mediated through its effect on the hepatic content of PGC-1 $\alpha$, which induced by SPIONs treatment in a dose-dependent manner, especially with SPION-PEG-2000 that showed a significant higher PGC-1 $\alpha$ level than control value at a dose of $66 \mu \mathrm{mol} \mathrm{Fe} / \mathrm{kg}$. PGC-1 $\alpha$, in turn, induces the expression of Tfam that directly ameliorates the mitochondrial biogenesis. The association between the PGC-1 $\alpha$, Tfam and mitochondrial biogenesis in the diabetic model has been confirmed by the in vivo [35] and in vitro studies [36]. The correlation studies indicated that the hepatic contents of PGC-1 $\alpha$ in SPIONs-treated rats are negatively correlated with FBG (Figure S3(a)) and HOMA-IR (Figure S3(b)) and positively correlated with PI3K (Figure S3(c)) which may imply that PGC-1 $\alpha$ pathway plays a role in the mechanism of SPIONs as an anti-diabetic agent.

Other important mediators that may participate in the anti-diabetic actions are adipocytokines. The present study demonstrated that SPIONs-treated diabetic rats showed significantly higher levels of adiponectin and lower RBP4 than untreated diabetic rats. These data confirm the involvement of adiponectin and RBP4 in the mechanisms of SPIONs action.

The anti-diabetic action of SPIONs may be partially mediated through its lipotropic effect as it significantly corrected the lipid profile in a dose-dependent manner and to a similar extent as metformin or even better. Considering SPIONs effect on the lipid components, it can be assumed as potential hypolipidemic agent, which will be of great advantage for the diabetic condition.

The review of literature indicated few studies were performed to explore the metabolic effects of SPIONs. In one study, Sharifi et al investigated the effect of SPIONs on the expression of two cluster genes involved in the development of obesity and T2DM in human primary adipocytes [9]. Interestingly, they found that most of genes associated with the risk for T2DM were down-regulated after treatment of adipocytes with SPIONs.

Despite the documented anti-diabetic effects of SPIONs in the present study, the hepatorenal toxicities are of major concerns. The present data indicate that, the treatment of diabetic rats with low dose (22 $\mu \mathrm{mol} \mathrm{Fe} / \mathrm{kg}$ ) of SPION-PEG-550 and SPION-PEG-2000 showed significant decline in serum AST and creatinine compared to untreated rats, while the higher doses of SPIONs (44 $\mu \mathrm{mol} \mathrm{Fe} / \mathrm{kg}$ and $66 \mu \mathrm{mol} \mathrm{Fe} / \mathrm{kg}$ ) showed a marked increase in serum AST 
activity compared to untreated rats or metformin-treated rats. The increase in hepatic manifestation (high AST) was more prominent in SPION-PEG-550 treated rats while the renal damage was more prominent in SPION-PEG-2000. This could be explained by the effect of the chain length of PEG on the SPIONs biodistribution, chain length of about $2 \mathrm{kDa}$ increases the blood circulation time and decreases the opsonization of SPIONs by kuppfer cells and subsequently their localization in liver and toxicity [12].

Most of the previous studies deal with acute or short-term daily exposure to SPIONs, however, in the present study, we use weekly doses of SPIONs coated with PEG of different lengths (550 and $2000 \mathrm{Da}$ ) for 4 weeks. The toxic effects evident only at high doses, 44 and 66 $\mu \mathrm{mol} \mathrm{Fe} / \mathrm{kg}$, while the lowest doses used (22 $\mu \mathrm{mol} \mathrm{Fe} / \mathrm{kg})$ appear to be somewhat safe and in the same time, have effective anti-diabetic actions.

\section{Conclusion}

SPIONs are powerful glucose and lipid-lowering factor that play important role in diabetic treatment. SPIONs produce their effect through multiple pathways. The used doses of SPIONs produce anti-diabetic effect equivalent to metformin; however, high doses have hepatorenal toxicities and may worsen the diabetic situation. So, further studies are necessary to explore the metabolic effects of SPIONs at lower doses than used in the present study, longer time intervals between doses (bi-weekly or monthly), and for longer durations. Also, application of SPIONs with the different coating may be more efficient and safer.

\section{Acknowledgments}

This work was partially supported by the Spanish Ministry of Science, Innovation and Universities (Grant PGC2018-095795-B-I00) and by the European Union's Horizon 2020 FET Open Programme (Grant no. 801305). The authors would like to acknowledge the use of Servicio General de Apoyo a la Investigación-SAI, Universidad de Zaragoza.

\section{Conflict of Interest}

There are no conflicts to declare. 


\section{Author contributions}

SA Shaker was involved in experiments, interpretation of the data and writing the article. LMA Ali was involved in the design of the experiments and writing the article. SA Mahmoud was involved in experiments and interpretation of the data. R Pinol and A Millan were involved in nanoparticle synthesis and characterization, and writing the article. MY Hanafy and MH Hemly were involved in the design of the experiments and interpretation of the data. MA Kamel was involved in the design of the experiments, interpretation of the data and writing the article.

\section{References}

[1] R. Hegazi, M. El-Gamal, N. Abdel-Hady, O. Hamdy, Epidemiology of and Risk Factors for Type 2 Diabetes in Egypt, Ann Glob Health. 81 (2015), pp. 814-20.

[2] M. Stumvoll, B.J. Goldstein, T.W. Van Haeften, Type 2 diabetes: principles of pathogenesis and therapy, Lancet. 365 (2005), pp. 1333-46.

[3] Z. Hedayatnasab, F. Abnisa, W.M.A. WanDaud, Review on magnetic nanoparticles for magnetic nanofluid hyperthermia application, Materials and Design. 123 (2017), pp. 17496.

[4] A. Marcu, S. Pop, F. Dumitrache, M. Mocanu, C.M. Niculite, M. Gherghiceanu , et al., Magnetic Iron Oxide Nanoparticles as Drug Delivery System in Breast Cancer, Applied Surface Science. 281 (2013), pp. 60-65.

[5] C. Rumenapp, B. Gleich, A. Haase, Magnetic Nanoparticles in Magnetic Resonance Imaging and Diagnostics, Pharm Res. 29 (2012), pp. 1165-79.

[6] H. Xu, Z.P. Aguilar, L.Yang, M. Kuang, H. Duan, Y. Xiong, et al., Antibody conjugated magnetic iron oxide nanoparticles for cancer cell separation in fresh whole blood, Biomaterials. 32 (2011), pp. 9758-65.

[7] A. Alkaladi, A.M. Abdelazim, M. Afifi, Antidiabetic activity of zinc oxide and silver nanoparticles on streptozotocin-induced diabetic rats, Int J Mol Sci. 15 (2014), pp. 2015 23.

[8] T.I. Shaheen, M.E. El-Naggar, J.S. Hussein, M. El-Bana, E. Emara, Z. El-Khayat, et al., Antidiabetic assessment; in vivo study of gold and core-shell silver-gold nanoparticles on streptozotocin-induced diabetic rats, Biomed Pharmacother. 83 (2016), pp. 865-75. 
[9] S. Sharifi, S. Daghighi, M.M. Motazacker, B. Badlou, B. Sanjabi, A. Akbarkhanzadeh, et al., Superparamagnetic iron oxide nanoparticles alter expression of obesity and T2Dassociated risk genes in human adipocytes, Sci Rep. 3 (2013), pp. 2173.

[10] L.M.A. Ali, M. Gutiérrez, R. Cornudella, J.A. Moreno, R. Piñol, L. Gabilondo, et al., Hemostasis disorders caused by polymer coated iron oxide nanoparticles, J Biomed Nanotechnol. 9 (2013), pp. 1272-85.

[11] L.M.A. Ali, R. Piñol, R. Villa-Bellosta, L. Gabilondo, A. Millán, F. Palacio, et al., Cell compatibility of a maghemite/polymer biomedical nanoplatform, Toxicol In Vitro. 29 (2015), pp. 962-75.

[12] L.M.A. Ali, P. Marzola, E. Nicolato, S. Fiorini, M.L. Heras Guillamón, R. Piñol, et al., Polymer-coated superparamagnetic iron oxide nanoparticles as T2 contrast agent for MRI and their uptake in liver, Future Sci OA. 5 (2019), pp. FSO235. doi: 10.4155/fsoa-20170054.

[13] P. Arosi, M. Basini, A. Barbaglia, R. Piñol, J.L.Murillo, A. Millán, et al., Effect of Spin Clustering on Basic and Relaxometric Properties of Magnetic Nanoparticles. J Nanosci Nanotechnol. 19 (2019), pp. 2950-62

[14] N. Pothayee, S. Balasubramaniam, R.M. Davis, J.S. Riffle, M.R.J. Carroll, R.C. Woodward, et al., Synthesis of 'ready-to-adsorb' polymeric nanoshells for magnetic iron oxide nanoparticles via atom transfer radical polymerization, Polymer. 52 (2011), pp.1356-66.

[15] K. Srinivasan, B. Viswanad, L. Asrat, C.L. Kaul, P. Ramarao, Combination of high-fat diet-fed and low-dose streptozotocin-treated rat: a model for type 2 diabetes and pharmacological screening, Pharmacol Res. 52 (2005), pp. 313-20.

[16] C. Marques, M. Meireles, S. Norberto, J. Leite, J. Freitas, D. Pestana, et al., High-fat dietinduced obesity Rat model: a comparison between Wistar and Sprague-Dawley Rat, Adipocyte. 5 (2015), pp. 11-21.

[17] A. Gajdosík, A. Gajdosíková, M. Stefek, J. Navarová, R. Hozová, Streptozotocin-Induced Experimental Diabetes In Male Wistar Rats, Gen Physiol Biophys. 18 (1999), pp. 54-62.

[18] Y.H. Choi, S.G. Kim, M.G. Lee, Dose-independent pharmacokinetics of metformin in rats: Hepatic and gastrointestinal first-pass effects, J Pharm Sci. 95 (2006), pp. 2543-52. 
[19] Y.X. Wang, S.M. Hussain, G.P. Krestin, Supermagnetic iron oxide contrast agents: physicochemical characteristic and application in MR imaging, Eur Radiol. 11 (2001), pp. 2319-31.

[20] R.G. Moses, M. Moses, K.G. Russell, G.M. Schier, The 75-g glucose tolerance test in pregnancy: a reference range determined on a low-risk population and related to selected pregnancy outcomes, Diabetes Care. 21 (1998), pp.1807-11.

[21] Z.Q. Wang, A.D. Bell-Farrow, W. Sonntag, W.T. Cefalu, Effect of age and caloric restriction on insulin receptor binding and glucose transporter levels in aging rats, Exp Gerontol. 32 (1997), pp. 671-84.

[22] P. Díez, M. González-Muñoz, M. González-González, R.M. Dégano, R. Jara-Acevedo, S. Sánchez-Paradinas, Functional insights into the cellular response triggered by a bile-acid platinum compound conjugated to biocompatible ferric nanoparticles using quantitative proteomic approaches, Nanoscale. 9(2017), pp.9960-9972.

[23] M.H. Shanik, Y. Xu, J. Skrha, R. Dankner, Y. Zick, J. Roth, Insulin resistance and hyperinsulinemia: is hyperinsulinemia the cart or the horse?, Diabetes Care. 31 (2008), pp. S262-8.

[24] T.J. Chahil, H.N. Ginsberg, Diabetic Dyslipidemia, Endocrinol Metab Clin North Am. 35 (2006), pp. 491-510.

[25] A.W. Dake, N.D. Sora, Diabetic Dyslipidemia Review: An Update on Current Concepts and Management Guidelines of Diabetic Dyslipidemia, Am J Med Sci. 351 (2016), pp. $361-5$.

[26] L. Pozzo, A. Vornoli, I. Coppola, C.M. Croce, L. Giorgetti, P.G. Gervasi, et al., Effect of HFD/STZ on expression of genes involved in lipid, cholesterol and glucose metabolism in rats, Life Sci. 166 (2016), pp.149-56.

[27] S. Skovsø, Modeling type 2 diabetes in rats using high fat diet and streptozotocin, J Diabetes Investig. 5 (2014), pp. 349-58.

[28] T.E. Graham, Q. Yang, M. Blüher, A. Hammarstedt, T.P. Ciaraldi, R.R. Henry, et al., Retinol-binding protein 4 and insulin resistance in lean, obese, and diabetic subjects, $\mathrm{N}$ Engl J Med. 354 (2006), pp. 2552-63.

[29] S. Polakof, T.P. Mommsen, J.L. Soengas, Glucosensing and glucose homeostasis: from fish to mammals, Comp Biochem Physiol B Biochem Mol Biol. 160 (2011), pp.123-49. 
[30] M. A Abdul-Ghani, R.A, DeFronzo, Pathogenesis of Insulin Resistance in Skeletal Muscle, J Biomed Biotechnol. 2010 (2010), pp. 476279.

[31] A.C. Panda, I. Grammatikakis, J.H. Yoon, K. Abdelmohsen, Posttranscriptional Regulation of Insulin Family Ligands and Receptors, Int J Mol Sci. 14 (2013), pp. 19202-29.

[32] O. Puig, R. Tjian, Transcriptional feedback control of insulin receptor by dFOXO/FOXO1, Genes Dev. 19 (2005), pp. 2435- 46.

[33] S. Wang, A. Kamat, P. Pergola, A. Swamy, F. Tio, K. Cusi, Metabolic factors in the development of hepatic steatosis and altered mitochondrial gene expression in vivo, Metabolism. 60 (2011), pp. 1090-9.

[34] R. Garesse, C.G. Vallejo, Animal mitochondrial biogenesis and function: a regulatory cross-talk between two genomes, Gene. 263 (2001), pp. 1-16.

[35] C. Kang, C.A. Goodman, T.A. Hornberger, L.L. Ji, PGC-1 $\alpha$ overexpression by in vivo transfection attenuates mitochondrial deterioration of skeletal muscle caused by immobilization, FASEB J. 29 (2015), pp.4092-106.

[36] P. Guo, H. Pi, S. Xu, L. Zhang, Y. Li, M. Li, et al., Melatonin Improves Mitochondrial Function by Promoting MT1/SIRT1/PGC-1 Alpha-Dependent Mitochondrial Biogenesis in Cadmium-Induced Hepatotoxicity In Vitro, Toxicol Sci. 142 (2014),182-95. 


\section{Figure legends}

Figure 1: Ferrofluids characterization (a) DLS distribution of hydrodynamic size in the ferrofluids (b) CryoTEM image of the SPION-PEG-2000 sample showing the polynuclear cores of the polymer coated nanoparticles. PEG polymer coating is not visible due to the low contrast of the polymer against the water background. In the inset, a high-resolution TEM image shows the maghemite crystal planes in a single iron oxide nanoparticle. (c) Histogram of the size distribution from TEM images.

Figure 2: Oral glucose tolerance test in control rats, untreated diabetic rats, metformin-treated diabetic rats, and different doses of SPION-PEG-2000 (a) or SPION-PEG-550 (b). Data are presented as mean $\pm \mathrm{SD}, \mathrm{n}=10$. Values and statistical analysis are shown in Table $\mathrm{S} 1$.

Figure 3: Hepatic content of Phospho-insulin receptor (a) P-IR (b) PI3K. *: significantly different from control rats by ANOVA $(\mathrm{p}<0.05)$, \#: significantly different from untreated diabetic rats by ANOVA $(\mathrm{p}<0.05)$, +: significantly different from metformin-treated rats by ANOVA $(\mathrm{p}<0.05)$, a: significantly different from diabetic rats treated with the $22 \mu \mathrm{mole} \mathrm{Fe} / \mathrm{kg}$ SPION-PEG by ANOVA $(\mathrm{p}<0.05), \$$ : significantly different from rats treated with the SPIONPEG2000 at the corresponding dose by t-test $(\mathrm{p}<0.05)$.

Figure 4: Hepatic content of phospho- glycogen synthase kinase $3 \beta . *$ : significantly different from control rats by ANOVA ( $<<0.05)$, \#: significantly different from untreated diabetic rats by ANOVA $(\mathrm{p}<0.05),+$ : significantly different from metformin-treated rats by ANOVA $(\mathrm{p}<0.05)$, a: significantly different from diabetic rats treated with the $22 \mu$ mole Fe/kg SPION-PEG by ANOVA $(\mathrm{p}<0.05), \$$ : significantly different from rats treated with the SPION-PEG2000 at the corresponding dose by $\mathrm{t}$-test $(\mathrm{p}<0.05)$.

Figure 5: Hepatic content of peroxisome proliferator-activated receptor gamma coactivator 1alpha content. *: significantly different from control rats by ANOVA $(\mathrm{p}<0.05)$, \#: significantly different from untreated diabetic rats by ANOVA $(\mathrm{p}<0.05),+$ : significantly different from metformin-treated rats by ANOVA $(\mathrm{p}<0.05)$, a: significantly different from diabetic rats treated with the $22 \mu$ mole Fe/kg SPION-PEG by ANOVA $(p<0.05)$, b: significantly different from diabetic rats treated with the $44 \mu$ mole Fe/kg SPION-PEG by ANOVA $(p<0.05), \$$ : significantly different from rats treated with the SPION-PEG2000 at the corresponding dose by t-test $(\mathrm{p}<0.05)$. 